\title{
Reduced heart rate variability following repair of tetralogy of Fallot
}

\author{
K A McLeod, W S Hillis, A B Houston, N Wilson, A Trainer, J Neilson, W B Doig
}

\begin{abstract}
Objective-To examine autonomic function as assessed by heart rate variability in patients 10 or more years after repair of tetralogy of Fallot, and to relate this to cardiac structure, function, and electrocardiographic indices.

Methods-Heart rate variability was measured by standard time domain techniques on a 24 hour Holter ECG in 28 patients, aged 12 to 34 years (mean 19.5), who had undergone repair of tetralogy of Fallot at least 10 years previously. Echocardiography was performed to assess left ventricular size and function, right ventricular size and pressure, and any proximal pulmonary arterial stenosis. Right ventricular function was evaluated by radionuclide scan. QRS duration, QT interval, and QT dispersion were measured on a standard 12 lead ECG. Measurements of heart rate variability were compared with values from 28 age matched healthy controls (mean age 19.9 years). Interrelations between variables were assessed using Pearson correlation coefficients and stepwise regression analysis.
\end{abstract}

Results-Heart rate variability was reduced, compared with values for age matched normal controls, in 12 of the 28 patients. Reduced heart rate variability was associated with increased age, increased right ventricular size and pressure, and widening of the QRS complex.

Conclusions-Reduced heart rate variability is a feature following repair of tetralogy of Fallot. It is associated with increasing age, impaired right ventricular haemodynamics, and widening of the QRS complex. Under these circumstances, reduced heart rate variability may be a marker for deteriorating right ventricular function. Increased QRS duration has been identified as a risk factor for sudden death following repair of tetralogy of Fallot, and impaired cardiac autonomic control may be one of the mechanisms involved. (Heart 1999;81:656-660)

Keywords: tetralogy of Fallot; heart rate variability; right ventricular function; congenital heart disease

UK

A Trainer

Department of Medical Physics, Royal Infirmary, Edinburgh, UK

J Neilson

Correspondence to: Dr McLeod.

Accepted for publication 8 July 1998

despite apparently satisfactory operative reps of tetralogy of Fallot, and it is believed that this may be the result of ventricular arrhythmias. ${ }^{1}$ The pathophysiology of electrical instability in these patients is not clear. There is no satisfactory method of identifying those at greatest risk of sudden death, although risk factors which have been identified include right ventricular dysfunction, persistent pulmonary regurgitation, and QRS prolongation on the surface ECG. ${ }^{34}$

The autonomic nervous system plays an important role in regulating the electrical stability of the heart. ${ }^{56}$ Measurements of heart rate variability provide a simple method of assessing cardiac autonomic function. ${ }^{78}$ Low heart rate variability in patients with ischaemic heart disease is a strong predictor for the generation of ventricular arrhythmias and sudden death. ${ }^{9}{ }^{10}$ In addition, there is a strong association between reduced heart rate variability and sudden death following myocardial infarction. ${ }^{11}{ }^{12}$ Drugs which increase heart rate variability appear to reduce the risk of sudden death. ${ }^{1314}$

Impaired autonomic function might be relevant to the increased incidence of sudden death after repair of tetralogy of Fallot. The object of this study was to examine autonomic function, as assessed by heart rate variability, in patients who had undergone repair of tetralogy of Fallot and to relate this to cardiac structure, function, and electrocardiographic indices.

\section{Methods}

We studied 28 patients (18 male, 10 female), aged 12 and 34 years (mean (SD), 19.5 (5.43)), who underwent repair of tetralogy of Fallot at least 10 years previously. All patients had undergone transannular patch repair through a ventriculotomy.

At the time of the study all patients were in sinus rhythm and none was taking antiarrhythmic treatment or any drug which might affect heart rate variability. None had coexistent renal disease, liver disease, or diabetes.

HEART RATE VARIABILITY

All patients underwent 24 hour Holter electrocardiographic monitoring using a 24 hour recorder (Reynold's Tracker III; Reynold's Medical Systems, Hertford, UK). The ECGs were analysed for arrhythmias. Heart rate variability was analysed on the recordings using commercial software (Reynold's Medical Systems). ${ }^{715}$ Variability was expressed as a count of the total number of differences between adjacent $R R$ intervals that were greater than $50 \mathrm{~ms}$ in a 24 hour ECG recording (sNN50). The results of sNN50 in patients with tetralogy of Fallot were compared with values from a group of 28 healthy individuals (14 male, 14 female), aged 12 to 34 years (mean 19.9 years)
ECHOCARDIOGRAPHY

Echocardiography was performed on all patients to assess the following: 
Table 1 Clinical details of the patients and electrocardiographic results

\begin{tabular}{|c|c|c|c|c|c|c|c|c|c|c|}
\hline Case & Sex & $\begin{array}{l}\text { Age } \\
\text { (years) }\end{array}$ & $A A O$ & $\begin{array}{l}H R V \\
(s N N 50)\end{array}$ & $R V D d$ & $R V p$ & $V S D$ & RVEFi & $Q R S$ & LVFS \\
\hline 1 & $\mathrm{~F}$ & 20 & $12 \mathrm{~m}$ & 15574 & 18 & 30 & Small & N/A & 180 & 26 \\
\hline 2 & M & 17 & $3 y$ & 9039 & 33 & 40 & No & 42.3 & 180 & 35 \\
\hline 3 & M & 21 & $7 \mathrm{y}$ & 8410 & 26 & 30 & No & 39 & 180 & 30 \\
\hline 4 & M & 34 & $17 \mathrm{y}$ & 1040 & 13 & 25 & No & 27 & 140 & 38 \\
\hline 5 & $\mathrm{~F}$ & 23 & $6 y$ & 833 & 40 & 50 & No & 38 & 110 & 25 \\
\hline 6 & M & 28 & $16 \mathrm{y}$ & 693 & 40 & 25 & Small & 33.5 & 230 & 16 \\
\hline 7 & M & 18 & $2 \mathrm{y}$ & 7685 & 39 & 45 & Small & 39 & 160 & 21 \\
\hline 8 & M & 18 & $3 \mathrm{y}$ & 3000 & 39 & 26 & Small & 47.5 & 200 & 35 \\
\hline 9 & M & 23 & $5 \mathrm{y}$ & 387 & 34 & 80 & No & 52 & 140 & 27 \\
\hline 10 & $\mathrm{~F}$ & 18 & $10 \mathrm{~m}$ & 6829 & 29 & 35 & No & 79 & 180 & 24 \\
\hline 11 & M & 25 & $7 y$ & 827 & 30 & 35 & No & 52 & 190 & 24 \\
\hline 12 & $\mathrm{~F}$ & 31 & $4 \mathrm{y}$ & 9771 & 34 & 22 & Small & 59 & 100 & 16 \\
\hline 13 & M & 15 & $12 \mathrm{~m}$ & 13249 & 31 & 30 & No & 39 & 180 & 29 \\
\hline 14 & $\mathrm{~F}$ & 27 & $7 \mathrm{y}$ & 503 & 32 & 45 & No & 63.8 & 160 & 34 \\
\hline 15 & $\mathrm{~F}$ & 16 & $10 \mathrm{~m}$ & 10372 & 32 & 35 & No & 50 & 160 & 21 \\
\hline 16 & M & 16 & $9 \mathrm{~m}$ & 8888 & 30 & 35 & No & 39.3 & 160 & 25 \\
\hline 17 & M & 23 & $3 y$ & 1286 & 34 & 35 & Small & 39.5 & 190 & 40 \\
\hline 18 & M & 18 & $2 \mathrm{y}$ & 1738 & 40 & 80 & No & N/A & 110 & 23 \\
\hline 19 & $\mathrm{~F}$ & 12 & $9 \mathrm{~m}$ & 10933 & 17 & 38 & Small & 30 & 170 & 40 \\
\hline 20 & M & 18 & $2 y$ & 4484 & 33 & 48 & No & 52 & 190 & 34 \\
\hline 21 & $\mathrm{~F}$ & 17 & $12 \mathrm{~m}$ & 5746 & 30 & 35 & Small & 38 & 150 & 25 \\
\hline 22 & $\mathrm{~F}$ & 15 & $3 \mathrm{y}$ & 1535 & 35 & 45 & No & 32 & 170 & 25 \\
\hline 23 & M & 15 & $3 \mathrm{y}$ & 8927 & 26 & 40 & Small & 31 & 200 & 27 \\
\hline 24 & $M$ & 13 & $12 \mathrm{~m}$ & 17952 & 23 & 25 & Small & 44 & 180 & 24 \\
\hline 25 & M & 18 & $2 y$ & 601 & 36 & 45 & Small & 35.3 & 190 & 41 \\
\hline 26 & $\mathrm{~F}$ & 14 & $2 \mathrm{y}$ & 10761 & 32 & 35 & No & 42 & 160 & 28 \\
\hline 27 & M & 22 & $2 y$ & 9724 & 29 & 35 & No & 62.3 & 160 & 35 \\
\hline 28 & M & 14 & $2 \mathrm{y}$ & 4658 & 30 & 45 & No & 37.5 & 160 & 27 \\
\hline
\end{tabular}

AAO, age at surgical repair; HRV, heart rate variability; LVFS, left ventricular fractional shortening; $\mathrm{m}$, months; N/A, not available; QRS, maximum QRS duration on a standard 12 lead ECG; RVDd, right ventriculsr dimension in diastole in $\mathrm{mm}$; RVEFi, right ventricular ejection fraction by radionuclide ventriculography; $\mathrm{RVp}$, right ventricular systolic pressure in $\mathrm{mm} \mathrm{Hg}$; $\mathrm{sNN} 50$, number of consecutive RR intervals $>50 \mathrm{~ms}$ on a 24 hour ECG; VSD, residual ventricular septal defect; $y$, years. structural, and electrical variables. The individual relations between the variables and heart rate variability were assessed using Pearson correlation coefficients. The relations with sex were assessed using the two sample $t$ test. Multiple linear regression analysis was used to produce a predictive model for heart rate variability based on the following variables: age, sex, left ventricular ejection fraction and fractional shortening (from echo), right ventricular size (from echo), right ventricular pressure (from echo), left ventricular ejection fraction (from isotope scan), right ventricular ejection fraction (from isotope scan), and measurements of QRS, QT and JT (from ECG).

\section{Results}

The results are shown in table 1 .

Mean sNN50 was reduced in patients with tetralogy of Fallot when compared with age matched normal controls (fig 1). The range of values was wider in patients with tetralogy of Fallot. Heart rate variability was less than the normal range in $12(43 \%)$ of the patients with tetralogy of Fallot.

ASSESSMENT OF THE RELATION WITH HEART RATE VARIABILITY

Correlation

The individual correlations between heart rate variability and the various measurements are shown in table 2. In patients with tetralogy of Fallot, no significant difference was found between the males and females with respect to heart rate variability. The only variables with significant individual correlation with heart rate variability were age, right ventricular end

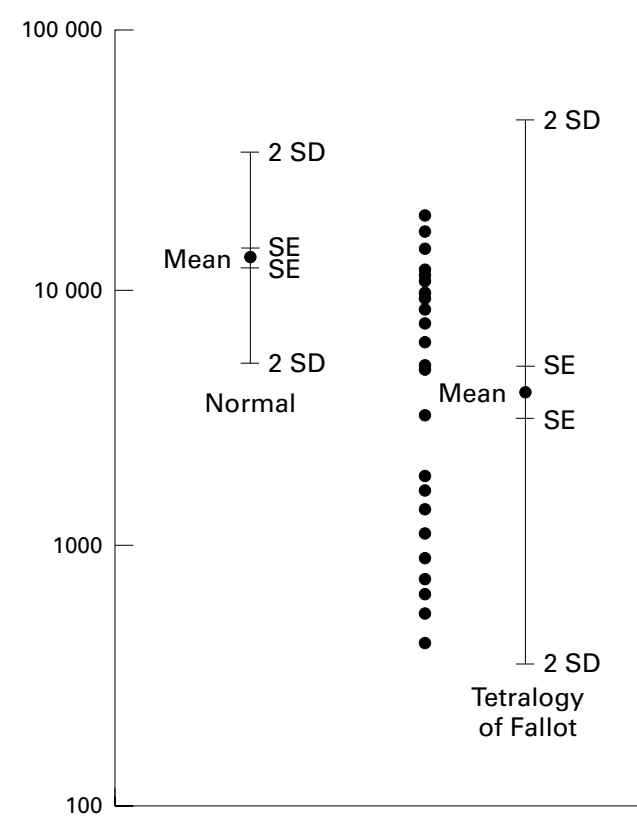

Figure 1 Heart rate variability following repair of tetralogy of Fallot plotted on a logarithmic scale against the range of values for normal controls aged 12-34 years. Mean sNN50 in patients with tetralogy of Fallot was significantly reduced compared with the age matched normal controls $(p<0.05)$. Heart rate variability was below the normal range in 12 of the patients with repair of tetralogy of Fallot. 
Table 2 Correlations between heart rate variability and the continuous explanatory variables

\begin{tabular}{|c|c|c|c|}
\hline Explanatory variable & $n$ & $\begin{array}{l}\text { Correlation } \\
\text { with HRV }\end{array}$ & $p$ Value \\
\hline Age & 28 & -0.472 & $0.011^{\star}$ \\
\hline Ejection fraction (LVEF) & 28 & 0.144 & 0.465 \\
\hline Fractional shortening (LVFS) & 28 & -0.161 & 0.412 \\
\hline Right ventricular size (RVDd) & 28 & -0.464 & $0.013^{\star}$ \\
\hline Right ventricular pressure $(R V p)$ & 28 & -0.432 & $0.022^{\star}$ \\
\hline QRS duration & 28 & 0.060 & 0.763 \\
\hline LVEF by isotope scan & 26 & 0.013 & 0.949 \\
\hline RVEF by isotope scan & 26 & 0.050 & 0.807 \\
\hline
\end{tabular}

There is a correlation between reduced heart rate variability and increasing age; reduced heart rate variability and increased right ventricular pressure; and reduced heart rate variability and increased right ventricular size.

HRV, heart rate variability; LVEF, left ventricular ejection fraction; LVFS, left ventricular fractional shortening; RVDd, right ventricular end diastolic dimension; RVEF, right ventricular ejection fraction.

diastolic dimension, and right ventricular pressure. There was no correlation between left ventricular function and heart rate variability.

\section{Stepwise regression analysis}

Using stepwise regression analysis, the first term entered into the model was age, which alone explained $25.2 \%$ of the differences in heart rate variability. Adjusting for age, the most significant of the remaining terms was right ventricular pressure, so this term was entered next into the model. Together these two terms accounted for $45.6 \%$ of the differences in heart rate variability. Finally, after adjusting for age and right ventricular pressure, the most significant of the remaining terms was QRS duration. Jointly the three variables accounted for $55 \%$ of the differences in heart rate variability. None of the remaining terms added any additional useful information.

\section{Best subsets regression}

Using the method of best subsets regression, the "best" three term model based on adjusted $R^{2}$ was still age, right ventricular pressure, and QRS duration, but reasonable predictive power could also be achieved by using models based on age, right ventricular pressure, and either right ventricular end diastolic dimension (adjusted $R^{2}=48.7 \%$ ) or right ventricular ejection fraction based on isotope imaging (adjusted $\left.R^{2}=47.4 \%\right)$.

Interrelations between explanatory variables All of the explanatory variables were plotted against each other using Pearson correlation coefficients. Significant correlations were found between right ventricular pressure and right ventricular end diastolic dimension $(p<0.05)$ as well as right ventricular pressure and QRS duration $(\mathrm{p}<0.05)$.

\section{Discussion}

Asymptomatic ventricular arrhythmias are common after repair of tetralogy of Fallot. Premature ventricular beats can be detected on Holter monitoring in around $45 \%$ of patients. ${ }^{17}$ Risk factors for asymptomatic ventricular arrhythmias include older age at repair, ${ }^{1819}$ increasing time since surgery, ${ }^{20}$ increased right ventricular pressures, and poor ventricular function. ${ }^{21}{ }^{22}$ The significance of asymptomatic ventricular arrhythmias is not clear. Although ventricular arrhythmias are a risk factor for sudden death following repair of tetralogy of Fallot, ${ }^{23}$ ventricular arrhythmias are common whereas sudden death is comparatively rare. At present there is no good way of identifying individuals at high risk of sudden death.

The autonomic nervous system has an important influence on myocardial stability. ${ }^{24}$ Sympathetic activation ${ }^{25}$ and parasympathetic impairment ${ }^{26}$ reduce the threshold for ventricular arrhythmias. Autonomic function may be measured by various techniques. ${ }^{27}{ }^{28}$ Cardiovascular reflex testing measures heart rate and blood pressure responses to various manoeuvres, including Valsalva, tilting, and drugs, but a major problem is that it suffers from lack of standardisation and is difficult to interpret. ${ }^{29}$ An alternative and more reliable method of assessing cardiac autonomic function is to measure heart rate variability. Different indices of heart rate variability reflect parasympathetic and sympathetic activity. ${ }^{30}$ Heart rate variability can be measured by either frequency or time domain techniques but domain parameters have mainly been used to correlate reduced heart rate variability with impaired left ventricular function. ${ }^{11}{ }^{26}$ The sNN50 is a count of the total number of differences between adjacent $R R$ intervals that are longer than 50 $\mathrm{ms}$ in a 24 hour electrocardiographic recording, and provides an index of parasympathetic function.

Although reduced heart rate variability has been associated with impaired left ventricular function, the relation between heart rate variability and right ventricular function has not previously been explored. One of the problems in evaluating this relation is that the geometry and trabeculation of the right ventricle make it difficult to measure its function accurately. ${ }^{31}$ In our study, we chose to measure right ventricular function by radionuclide using first transit studies, as this is a relatively reproducible and non-invasive technique, ${ }^{32}$ and has been used previously to evaluate right ventricular function in patients with chronic lung disease $^{33}$ and tetralogy of Fallot. ${ }^{34}$

Our study shows that reduced heart rate variability may be found in patients 10 years or more after repair of tetralogy of Fallot. Unlike previous studies in patients with ischaemic heart disease, reduced heart rate variability following repair of the tetralogy is not related to impaired left ventricular function. Instead it is associated with increasing age and indices of impaired right ventricular haemodynamics, including increased right ventricular dimension, increased right ventricular pressure, and, to a lesser extent, right ventricular ejection fraction, as measured by radionuclide scan. The association of reduced heart rate variability with impaired right ventricular haemodynamics suggests the former might be useful as a simple non-invasive indicator of deteriorating 
right ventricular function in patients with tetralogy of Fallot. This could be helpful-for example, when trying to determine the timing of valve replacement in patients with free pulmonary regurgitation.

Gatzoulis et al described the measurement of QRS and QT duration as well as JT, QRS, and QT dispersion as a method of identifying patients at risk of ventricular arrhythmias and sudden death late following repair of tetralogy of Fallot. ${ }^{44}$ When these measurements were applied to our cohort of 28 patients we found that all had at least one increased value, implying an increased risk of ventricular arrhythmia, but only one of our patients had a ventricular arrhythmia (ventricular premature beats) on Holter monitoring. None of the others had either documented ventricular arrhythmias or symptoms of arrhythmias. A major problem with measuring QT and JT interval and dispersion in these patients is the difficulty in determining the end of the $\mathrm{T}$ wave and discriminating a $\mathrm{T}$ wave from a $\mathrm{U}$ wave. Of all the measurements from the surface ECG, Gatzoulis et al found that the best predictor of sudden death was a QRS duration of $>180 \mathrm{~ms}$. In our study, prolonged QRS was the only electrocardiographic finding associated with reduced heart rate variability. In addition we found a positive correlation between right ventricular end diastolic dimension on echocardiography and QRS duration, as well as between increased right ventricular pressure and QRS duration. A similar relation was described by Gatzoulis et al, who found a strong correlation between QRS duration and cardiothoracic ratio in patients with repaired tetralogy of Fallot. They suggested that increased QRS may only be a surrogate' risk factor for sudden death in that if the right ventricle is dilated and develops tachycardia, the patient is more likely to become haemodynamically compromised and die. However, the finding that a dilated right ventricle and increased right ventricular pressures are also associated with reduced heart rate variability suggests that impaired right ventricular function in itself might be responsible for electrical abnormalities. The present findings represent the first report of such a relation.

Whereas only a prospective study would show whether reduced heart rate variability is an independent risk factor for late sudden death in patients after repair of tetralogy of Fallot, its association with other known risk factors for sudden death-including increasing age, a dilated right heart, raised right heart pressures, and wide QRS on surface ECGindicate that autonomic dysfunction may play an important role in myocardial instability in these patients.

Heart rate variability is extremely easy to measure on a 24 hour ECG using commercially available software. Many patients will undergo 24 Holter monitoring after repair of tetralogy of Fallot as part of routine follow up investigations, and it adds little extra time to do heart rate variability analysis. Low heart rate variability may alert the clinician to problems of impaired right ventricular function and the possibility of increased risk of serious arrhythmias, and suggest the need for more vigilant follow up.

1 Quattlebaum TG, Varghese J, Neill CA, et al. Sudden death among post-operative patients with tetralogy of Fallot: a follow-up study of 243 patients for an average of twelve follow-up study of 243 patien.

2 Stevenson WG, Klitzer T Perloff JK. Electrophysiological abnormalities. In: Perloff JK, Child JS, eds. Congenital heart disease in adults. Philadelphia: WB Saunders, 1991:259-95

3 Deanfield JE, McKenna WJ, Presbitero P, et al. Ventricular arrhythmia in unrepaired and repaired tetralogy of Fallot; relation to age, timing of repair and haemodynamic status. Br Heart f 1984;52:77-81.

4 Gatzoulis MA, Till JA, Somerville J, et al. Mechanoelectrical interaction in tetralogy of Fallot: QRS prolongation relates to right ventricular size and predicts malignant ventricular arrhythmias and sudden death. Circulation
1995;92:231-7.

Verrier RL, Lown B. Sympathetic-parasympathetic interactions and ventricular stability. In: Schwartz PJ, Brown AM, Malliani A, Zanchetti A, eds. Neural mechanisms in cardiac
arrhythmias. New York: Raven Press, 1975:75-86.

6 Schwartz PJ, Billman GE, Stone HL. Autonomic mechanisms in ventricular fibrillation induced by myocardial ischaemia during exercise in dogs with healed myocardial infarction. An experimental preparation for sudden death. Circulation 1984;69:790-800.

7 Ewing DJ, Neilson JMM, Travis P. New method for assessing cardiac parasympathetic activity using 24-hour electrocardiograms. Br Heart $\mathcal{F}$ 1984;52:396-402.

8 Ewing DJ, Neilson JMM, Shapiro CM, et al. 24 Hour heart rate variability: effects of posture, sleep and time of day in normal subjects and comparison with bedside autonomic function tests in diabetic patients. Br Heart f 1991;65:23944.

9 Kent KM, Smith ER, Redwood DR, et al. Electrical stability of acutely ischaemic myocardium. Influences of heart rate and vagal stimulation. Circulation 1973;47:291-8.

10 Goldstein RE, Beiser GD, Stampfer M, et al. Impairment of autonomically mediated heart control in patients with carautonomically mediated heart control in p
diac dysfunction. Circ Res 1975;36:571-8.

11 Kleiger RE, Miller JP, Bigger JT, et al. Decreased heart rate variability and its association with increased mortality after acute myocardial infarction. Am f Cardiol 1987;59: 256-62.

12 Bigger JT, Fieiss JL, Steinman RC, et al. Frequency domain measures of heart period variability and mortality after myocardial infarction. Circulation 1992;85:164-71.

13 Flapan AD, Nolan J, Neilson JMM, et al. Effect of captopril on cardiac parasympathetic activity in chronic heart failure secondary to coronary artery disease. Am $\mathcal{f}$ Cardiol 1992;69:532-5.

14 Vybiral T, Bryg RJ, Maddens ME, et al. Effects of transdermal scopolamine on heart rate variability in normal subjects. Am 7 Cardiol 1990;65:604-8.

15 Schetchtman VL, Kluge KA, Harper RM. Time domain system for assessing variation in heart rate. Med Biol Eng Comput 1988;26:367-73

16 Pye M, Quinn AC, Cobbe SM. QT interval dispersion; a non-invasive marker of susceptibility to arrhythmia in patients with sustained ventricular arrhythmias? Br Heart $\mathcal{f}$ 1994;71:511-14.

17 Vaksman G, Fournier A, Davignon A, et al. Frequency and prognosis of arrhythmias after operative "correction" of tetralogy of Fallot. Am f Cardiol 1990;66:346-9.

18 Sullivan ID, Presbitero P, Gooch VM, et al. Is ventricular arrhythmia in repaired tetralogy of Fallot an effect of operation or a consequence of the course of the disease? $\mathrm{Br}$ Heart f 1987;58:40-4.

19 Ross BA. From the bedside to the basic science laboratory; arrhythmias in Fallot's tetralogy. F Am Coll Cardiol 1993;21:1738-40.

20 Garson A, Gillette PC, Gutgesell HP, et al. Stress-induced ventricular arrhythmias after repair of tetralogy of Fallot. Am f Cardiol 1980;46:1006-12.

21 Garson A, Randall DC, Gillette PC, et al. Prevention of sudden death after repair of tetralogy of Fallot: treatment of sudden death after repair of tetralogy of Fallot: treatment of
ventricular arrhythmias. $7 \mathrm{Am}$ Coll Cardiol 1985;6:221-7.

ventricular arrhythmias. $\mathcal{F}$ Am Coll Cardiol 1985;6:221-7.
22 Joffe $\mathrm{H}$, Georgeakapoulos D, Celemajer DS, et al. Late ventricular arrhythmia is rare after early repair of tetralogy of Fallot. F Am Coll Cardiol 1994;23:1146-50.

23 Wessel HU, Bastanier CK, Paul MH, et al. Prognostic significance of arrhythmia in tetralogy of Fallot after intracardiac repair. Am $\mathcal{F}$ Cardiol 1980;46:843-8.

24 Verrier RL, Thompson PL, Lown B. Ventricular vulnerability during sympathetic stimulation; role of heart rate and blood pressure. Cardiovasc Res 1978;8:602-10.

25 Lown B, Tante JV, Reich P, et al. Basis for recurring ventricular fibrillation in the absence of coronary heart disease and its management. N Engl f Med 1976;294:623-9.

26 Nolan J, Flapan AD, Capewell S, et al. Decreased cardiac parasympathetic activity in chronic heart failure and its parasympathetic activity in chronic heart failure and its
relation to left ventricular function. Br Heart $\mathcal{F} 1992 ; 67$ : relation $482-5$.

27 Eckberg DL. Parasympathetic cardiovascular control in human disease: a review of methods and results. Am $\mathcal{F}$ Physiol 1980;239:H581-93. 
28 Hainsworth R. Noninvasive measurement of cardiovascular reflexes in humans. Clin Sci 1990;78:437-43.

29 Ewing DJ, Martyn CN, Young RJ, et al. The value of carc vascular autonomic function tests: 10 years experience in diabetes. Diabetes Care 1985;8:491-8.

30 Malliani A, Lombardi F, Pagani M. Power spectrum analysis of heart rate variability: a tool to explore neural regulatory mechanisms. Br Heart f 1994;71:1-2.

31 Oldershaw P. Assessment of right ventricular function and its role in clinical practice. Br Heart $\mathcal{F} 1992 ; 68: 12-15$.

32 Berger HJ, Matthay RA, Loke J, et al. Assessment of cardiac performance with quantitative radionuclide angiography: right ventricular ejection fraction with reference to findings in chronic obstructive pulmonary disease. Am f Cardiol 1978;41:897-905

33 Reduto LA, Berger HJ, Johnstone DE, et al. Radionuclide assessment of right and left ventricular exercise reserve after total repair of tetralogy of Fallot. Am $\mathcal{F}$ Cardiol 1980; 45:1013-18.

34 Gatzoulis MA, Till JA, Redington AN. Depolarisationrepolarisation inhomogeneity after repair of tetralogy of Fallot: the substrate for malignant tachycardia? Circulation 1997;95:401-4.

\section{False aneurysm following balloon dilatation of multiple right pulmonary artery stenoses}

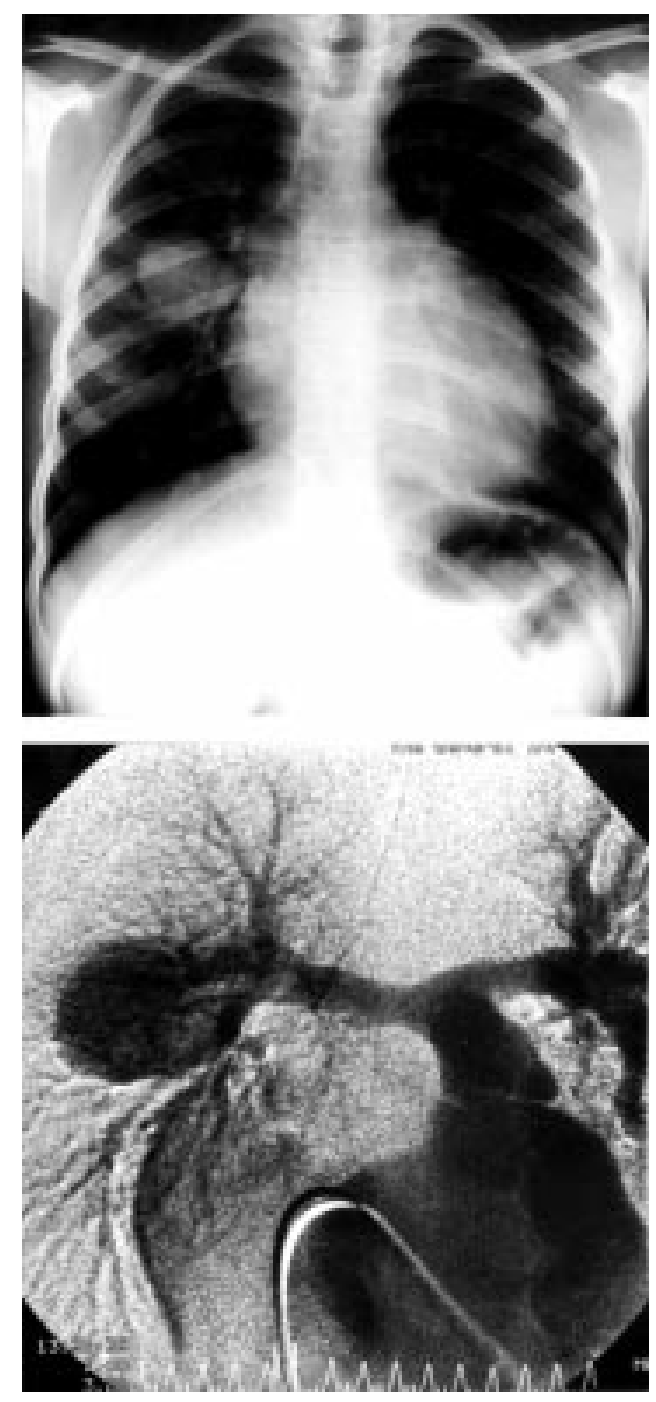

An 11 year old girl with tetralogy of Fallot, who was initially palliated with a Waterston shunt and later underwent total correction, presented with bilateral branch pulmonary artery stenoses. She had two repeat balloon dilatations for residual pulmonary artery stenoses 24 and 32 months after corrective surgery. A $15 \mathrm{~mm}$ balloon was used to dilate the right pulmonary artery on both occasions. Although the right pulmonary artery was entered with difficulty using a superstiff wire, there was no untoward effect following dilatations.

Chest radiography showed a spherical shadow in the right lung when she was reviewed in the outpatients clinic four years after the procedure. She reported one episode of chest pain but no other symptoms before this finding.

Selective pulmonary angiography showed a large saccular false aneurysm attached to the right pulmonary artery with a wide pedicle. The lesion was thought to have occurred following the last dilatation procedure resulting from a small perforation in the right pulmonary artery.

Continuing expansion of the mass, compression to surrounding structures, infection, and in particular spontaneous rupture are among the most feared complications of false aneurysms. Surgery is therefore needed for most of these lesions. The patient is currently well and awaiting surgical resection of the false aneurysm.

O UZUN

J THOMSON J M PARSONS 